This is a self-archived version of an original article. This version may differ from the original in pagination and typographic details.

Author(s): Valo, Maarit; Mikkola, Leena

Title: Focusing on Workplace Communication

Year: 2020

Version: Accepted version (Final draft)

Copyright: (c) 2020 Taylor \& Francis

Rights: In Copyright

Rights url: http://rightsstatements.org/page/lnC/1.0/?language=en

Please cite the original version:

Valo, M., \& Mikkola, L. (2020). Focusing on Workplace Communication. In L. Mikkola, \& M. Valo (Eds.), Workplace Communication (pp. 3-14). Routledge.

https://doi.org/10.4324/9780429196881-1 
Valo, Maarit; Mikkola, Leena (2020). Focusing on Workplace Communication. In Mikkola, Leena; Valo, Maarit (Eds.) Workplace Communication. New York: Routledge, 3-14. DOI: $10.4324 / 9780429196881-1$

\title{
1 Focusing on workplace communication
}

\section{Maarit Valo and Leena Mikkola}

\begin{abstract}
Communication has a constitutive role in the workplace; in workplace communication the organization comes into being. In workplace communication workers create and negotiate meanings and a shared understanding of important work-related issues. Communication is also essential for a functional working environment. Especially in knowledge-based work members of the workplace aim at success, efficiency, and productivity by discussing, conversing, debating, and providing and receiving feedback. Hence, when striving to establish a healthy workplace with high levels of satisfaction and well-being, one has to understand the dynamics of workplace communication. This chapter examines interpersonal communication and social interaction in the workplace and the impact they have on the work organization and its activities. The chapter explores the fundamental perspectives on workplace communication: the constitutive perspective of communication, coordinated management of meaning, interactional frames, task-related, relational, and identity dimensions of communication, and the discourse perspective as well as the structuration perspective on communication. The chapter also presents the structure of the book.
\end{abstract}

Keywords: interpersonal communication, organizational communication, social interaction, working life, workplace communication

\section{Introduction}

Human communication has a constitutive role in the workplace: It is in workplace communication that the organization comes into being. Through workplace communication, we construct a joint understanding of important work-related issues. Mutual interaction allows us to negotiate the meanings of our joint work and set common goals. Communication is 
essential for a functional working environment as well. We aim at success, efficiency, and productivity at work by discussing, conversing, debating, and providing and receiving feedback. Hence, when striving to establish a healthy workplace with high levels of well-being and satisfaction, we have to understand the dynamics of workplace communication.

Communication is involved in all forms of human cooperation, and it is therefore embedded with versatile meanings. In working life, communication in its broadest sense may bring to mind various institutions, from media corporations to small communication companies. Communication may also refer to social media and information and communication technologies. In organizational contexts, communication may involve such activities as human resources communication, external stakeholder relations, or marketing. Regarding the workplace, however, the focus of communication is on interpersonal relations and social interaction among the members of the workplace. In the various settings of our daily work, communication ranges from internal informing to problem-solving, from leadership communication to teams and groups, and from strategic decision-making to colleagues' informal discussions over coffee or lunch. This book is about workplace communication in all its dynamics and variability.

Even though there is a long tradition of research on interpersonal communication in private life settings, the overarching interpersonal approach to workplace communication adopted here is still novel. This book contributes to the understanding of working life by reviewing and analyzing the knowledge of interpersonal communication in the workplace. Not too long ago, it was customary to refer to employees' mutual interaction as "informal communication", "the grapevine", or "corridor conversations". From the leaders' or managers' point of view, employees' conversations about organizational issues were regarded as unimportant or even harmful, because such conversations do not necessarily fall in line with "official communication". Today we know better. It is indeed through interpersonal communication that people become aware of each other, build connections to other people, construct and maintain relations with them, and develop a sense of belonging to the same social system. In this book, this social system in question is the shared workplace.

By workplace people often mean the physical environment where the work is performed. Formerly, workplace interactions were viewed as communication situations involving coworkers in the same geographical location. However, changes in working life have altered 
our perceptions about the workplace. Work can be done at different times and locations, and the associated interactions can be face-to-face, technology-mediated, or both. In particular, the fragmentation of organizational structures, the increase in international networking, and remote, mobile, and flexible work have enriched our understanding of where work can take place. We can also no longer assume that our closest colleagues will be those working in close geographic proximity. Instead, a close coworker may carry out their work remotely, even in another country or continent. Therefore, the workplace is here understood as the experienced workplace, consisting of work-related connections, relationships, teams, and groups. Coworkers convene on the basis of work tasks, in meetings, and in other kinds of face-to-face and technology-mediated settings. Both of the latter are explored in this book.

For many, the workplace is a community of coworkers. At work, we hope to feel a sense of belonging and togetherness, and we expect to have opportunities to share goals and values with others. Viewing the workplace as a community highlights its members' positive attitudes and commitment. Hence, the workplace is a small or large group of people who

- are interdependent;

- exert a mutual influence on each other;

- share work goals and tasks;

- cooperate with each other in completing and achieving them.

Coworkers often trust, care about, and support each other. However, the workplace as a community hardly can exist without disputes, conflicts, and problematic relationships. Managing them is a challenge for all organizations. This book focuses on both the positive and negative phenomena of workplace communication.

Workplaces are situated in many kinds of organizations, from small start-up companies to global corporations, and from public, nonprofit, institutional organizations to small and medium-sized enterprises. The context of the workplace is manifold. Obviously, the form and structure of a given organization have various effects on workplace communication. Challenges in communication appear in different forms in different organizations. Employees may work full-time, part-time, or in shifts. They may have permanent or fixed-term contracts, or they may be engaged in projects or on-demand platform work. In addition, the workplace 
can be a stable community with low employee turnover and long-term coworkers, or it can be a loose network with constantly changing workmates.

At the workplace level, however, interpersonal relationships, communication in groups and teams, and all other forms of social interaction in the work community are of vital integrative importance. Functional difficulties encountered in daily work do not usually originate from unsuitable structures of the organization. Neither do they stem from bad chemistry between people or coworkers being unmanageable or too different from one another. Instead, such difficulties often result either from the untapped potential of communication or imperfect communication practices.

This book concentrates especially on communication in knowledge-based work. Knowledge work is generally characterized by the use, creation, and sharing of expert knowledge. It involves processing nonroutine tasks and problems, which require nonlinear, creative, and improvement-oriented thinking. Usually, knowledge work involves problem-solving, cooperation, networking, substantial use of information and communication technology (ICT), and learning in the workplace (Reinhardt, Schmidt, Sloep \& Drachsler 2011). Knowledge workers may be traditional academic professionals (e.g., in health care, education, social service, academia), or they may be qualified experts in various novel fields of work, such as in occupations developed along the advances of ICT (Carvalho \& Santiago 2016). However, the notion of knowledge work can easily be extended to cover all kinds of nonroutine work that requires communication, knowledge, and learning.

This book offers concepts, structures, and explanations related to issues that all knowledge workers experience in their workplace. The book's aim is to open an inquiry into the phenomena of interpersonal communication and social interaction: What they are, what research says about them, and what their impact on workplace communication is.

\section{Creating Realities and Coordinating Meanings}

Interpersonal communication is about producing and interpreting messages - and simultaneously about making sense of and managing social situations. The goal of mutual encounters is usually to build and coordinate a fluid and consistent interaction. Interaction is constructed in successive reciprocal messages created by means of verbal and nonverbal codes. 
Communication is sometimes understood as a transmission of information through the sending and receiving of messages. This transmission perspective limits communication to delivering information from a source to a receiver through input, process, and output. Although the linear transmission model is appealing and may sometimes be useful, because it can encourage attention to building and conveying messages carefully and effectively, this model clearly oversimplifies the dynamics of communication in the context of daily work. This book is based on the constitutive perspective of communication. (For an overview of the many traditions of communication theory, see Craig and Muller 2007.)

The constitutive perspective of communication emphasizes the process of creating, interpreting, and negotiating shared meanings in interaction. Communicators do not separately occupy the roles of sender and receiver; rather, they simultaneously constitute the social process of communication. In an interpersonal relationship, for example, communication does not take place between communicators, but the relationship exists because communication takes place - relationships are communication (Manning 2014). Communication is not only about expressing social realities; instead, it is the central means of creating them. The constitutive approach to communication acknowledges that communication creates, maintains, and shapes our social worlds, including our relationships (Baxter 2004). Participants in interpersonal communication make sense of the situation and its components - including fellow participants and their messages, past interactions with them, and the goals of the current interaction - by imputing meanings to them. Meaning is indeed the basic unit of communication and a primary source of human action (Drazin, Glynn, \& Kazanjian 1999). In interactions, we react and respond to meanings. At the same time, we perceive both our own and our partner's actions as part of the larger social world.

Meanings are coordinated in social interaction. Coordination is an implicit or explicit process in which parties provide and express potential interpretations of elements of the interaction (including the content of the messages; speech acts such as statements, opinions, questions, compliments, and promises; the ways in which participants speak; relationships; situational features) and other parties either accept the interpretations or provide new ones. This process is called coordinated management of meaning (Pearce 2007; Pearce \& Cronen 1980). Achieving shared meanings is not always easy, because we bring certain personal meanings to the interaction. However, interactions are fundamentally about searching for interpersonal meanings (Cushman \& Whiting 1972). In the workplace, we sometimes devote a great deal of 
our time to striving for shared meanings and negotiating them. We can certainly participate in interactions without reaching actual mutual understanding, but in meaningful relationships with close coworkers, or in the face of issues considered central and valuable in the workplace, establishing meanings shared by all participants is of vital importance.

In social interaction, participants seek to understand how to define the communication situation and how to act according to related social expectations. In these situations, communicators apply frames. Frames are socially constructed structures of meanings that are used as "schemata of interpretations" (Goffman 1974, 21). Interactional frames are socially constructed premises of situations and of the behavioral expectations associated with them, and these structures are then represented in interaction (Dewulf et al. 2009). Frames help people organize the expectations related to a social situation (Goffman 1974) when they are seeking interpretive cues (Bateson 1972). Different frames generate different courses of action. For instance, in interprofessional interaction, different professional frames produce different interpretations of the content of current issues and their importance for the work processes. This variability often leads to misunderstandings or disagreements. Achieving a shared reality requires that both frames and the meanings arranged in them are discussed.

\section{Task-Related, Relational, and Identity Dimensions of Workplace Interaction}

Communication is a multidimensional process in which task-related, relational, and identity goals appear at the same time (Clark \& Delia 1979). In social interaction, meanings are simultaneously imputed to tasks, mutual relationships, and communicators' identities. In the workplace, it is obvious that task-related communication is essential to the work. Employees communicate to achieve their work goals, that is, to obtain information, solve problems, and make plans. They create and negotiate meanings associated with their work in order to develop a mutual understanding of it. This kind of task-oriented communication is the foundation of work in knowledge-based organizations.

Workplace communication is characterized by the principle of collaboration. Collaboration enables the pursuit of objectives that are often complex and demanding. In fact, managing the objectives of work is an important function of workplace interaction, because in communication the objectives are made sense of and become shared. Other important taskrelated functions include knowledge sharing, knowledge management, idea generation, 
problem-solving, and decision-making, as well as managing disagreements. These functions are actualized in both face-to-face encounters and digital environments characterized by technology-mediated communication.

When discussing work-related tasks, participants also pursue their relational goals and create meanings for their mutual relationships. This is called relational communication (Parks 1977). It occurs simultaneously with task-related issues, and it is enacted by verbal and nonverbal relational messages, such as expressions of appreciation and control, liking and disliking, or closeness and distance. Through relational messages, we interpret how others perceive us, respond to and behave towards us, and view our position. Relational communication plays a major role in building a functional and effective workplace; focusing solely on task-related communication does not produce beneficial workplace communication. For example, creating a supportive working environment and managing conflicts require pertinent relationshiporiented procedures.

The key relational function of interpersonal communication in the workplace is relationship forming and maintenance. Even though workplace communication mostly serves the successful performance of work tasks and the achievement of objectives, it also supports the development of a variety of interpersonal relationships. In knowledge-based work, it is often the case that all the daily tasks are carried out in interpersonal relationships. Relationships are the basic mutual connections in work, but they also construct groups, teams, organizations, and networks. Workplace relationships are indeed manifold: Leader-follower relationships and peer coworker relationships are of course common, and there are also mentoring and supervisory relationships. Some of the relationships may be characterized as workplace friendships, and romantic relationships sometimes develop as well (Sias 2009). Nevertheless, the workplace is a place for work. The primary goal should not be to nurture one's relationships, to bond, to have a good time, or to amuse oneself. Establishing high-quality relationships should be for the sake of a well-functioning workplace.

Identity communication in the workplace involves both task-related and relational communication. Identity is a multifaceted and ever-changing social phenomenon that is expressed and interpreted in social interaction. Meanings for one's identity are created, and they include both the personal sense of self (subjective identity) and the perceptions that others have of the person (ascribed identity). Relational identities are constructed in specific 
relationships and attached to them, because they represent the person as a relational counterpart (Hecht, Warren, Jung, \& Krieger 2005). In the workplace, identity communication is related mainly to professional identity. In knowledge work, strong professional identities are often of great importance to employees, and identity goals are intentionally pursued.

Task-related, relational, and identity dimensions occur in interaction simultaneously. Hence, there are various opportunities to develop a good communication environment where professional identities are valued. There is no need for after-work happenings or "forced fun" activities during office or free time, because satisfactory interpersonal relationships can be constructed while employees work with each other. Coworkers do not need to be loved; good interaction in the workplace is simply enough. The triad of task, relational, and identity goals suggests that it is important to keep them in balance in workplace communication. Nevertheless, task-related goals are always the basis for building a well-functioning workplace. It is crucial to have a shared understanding of work objectives, but it is not that crucial to decorate a nice break room for employees. If relational goals take more effort than task-related goals, the solutions for a functional workplace have been sought in the wrong direction. Moreover, in start-up companies, in which the business idea may be tightly connected to the entrepreneur's personal vision and to their personal connections, it is important to ensure that task-related communication has the primary role. The personal vision has to be clearly shared and refined into task-related goals.

\section{Structuration, Discourses, and Workplace Culture}

Every workplace has its own kind of workplace culture. Workplace culture (or organizational culture) is constructed as "the set(s) of artifacts, values, and assumptions that emerges from the interactions of organizational members" (Keyton 2011, 28). Workplace culture is constructed and manifested in communication - and communication also changes it. It is a shared social experience that develops in workplace interactions and is based mainly on how employees perceive and experience their participation in the organization (Keyton 2014).

Workplace culture is an overarching concept that encompasses numerous aspects of workplace communication. Its multilevel constituents include communication values, communication practices in relationships, teams, meetings and other encounters, interpersonal behaviors of coworkers (e.g., support, humor, trust), dominant discourses, leadership communication, and 
forms of employee participation and influence. Assumptions regarding preferred, desirable, and undesirable communication behavior and practices are embedded in workplace culture. Basic assumptions are seldom conscious, but they nevertheless guide employees' interactions. When assumptions become shared and collective, they form implicit rules.

The formation of such rules happens over time via structuration processes. The structuration perspective of communication (based on Giddens 1984) explores the role of communication in creating structures into social life. Structures are formed when communicators coordinate their mutual actions in the pursuit of collective goals. Social constructs such as relationships, groups, and organizations are produced and reproduced - and also altered - through their structures. Structures are manifested via implicit or explicit rules in communication. Social interaction is guided by these rules, which are in turn shaped by interaction (Poole \& McPhee 2005). In the workplace, for example, one member may repeatedly take the role of chair in meetings. This action creates a collective assumption - a rule - that a chair is needed. Once the rule is formed, it is maintained and starts to guide meetings in the workplace.

Rules are often maintained unconsciously - they are the hidden side of structures. However, rules become visible in communication practices, which are then the visible side of structures. For example, the rule of low hierarchy is present in the practice of having frequent informal discussions, and the rule of cooperation becomes visible in the practices of planning and organizing meetings with equal involvement and participation. In workplaces, established rules tend to have a long history, because structuration always takes time. In addition, there may be unsuitable rules guiding communication behavior. For instance, hierarchy-maintaining structures may exist even though the organizational structure is explicitly based on self-directed teams. However, rules can also be changed in workplace interactions. Interactions have the power to strengthen or weaken the rules prevailing among the work community. Therefore, first becoming aware of the rules and then behaving otherwise, acting against the rules, or introducing new communication practices will gradually change the rules.

Workplaces exist in the larger context of working life, which creates a frame for working. Economic facts, employment regulations, and occupational agreements, as well as the industry or work sector, constitute the societal context and have an impact on both work and workplace communication. In the workplace communication these societal circumstances may echo as societal discourses. Discourses are systems of thought in a particular sociohistorical context, 
but they are also language-in-use in social interaction (Alvesson \& Kärreman 2000). They form internally coherent systems of meanings that are manifested and also compete in interpersonal communication (Baxter 2011). Discussions of the boundaries between work and private life, discussions of globalization, and discussions about economic necessities are some examples of the discourses that have cultural and societal origins and that become visible in workplace interaction.

In workplace communication, new discourses are also created and maintained (see Fairhurst 2011). Our workplace culture may include constant discourses of time-spending meetings, of inauthentic technology-mediated communication, of being too busy, or of receiving excessive emails. These discourses may even be formed as explicit rules regarding favored conversation topics in the workplace. However, the culture of a workplace can be reflected on and evaluated, and its elements can be made visible. Discourses prevalent in daily work can be judged on the basis of their rationality. If they are not justified, the communication practices motivating them may need to be changed.

\section{Perspectives on Workplace Communication}

Interaction is a positively charged concept. Interactivity is one of the most favored values in communication: Engaging in interaction, being interactive, creating interactivity, and communicating interactively are highly regarded. For example, expressions such as "leading should be interactive" and "dialogue is needed in the workplace" indicate the generally positive attitude towards communication. Favoring interpersonal relations and providing plenty of opportunities to engage in interactions clearly contribute to well-functioning workplace communication.

However, interaction in itself does not necessarily entail positive outcomes. Even though communication is meant to be interactive, it is not automatically perceived as interactive by participants. Meetings, negotiations, teams, and dyadic encounters can very well be experienced and evaluated as noninteractive: Some communicators may not be attentive or involved, may not listen to other participants, or may attempt to dominate the floor. There may be a hidden or open conflict that is not being discussed or treated in a reasonable way. Social interaction with an undesirable coworker may cause stress and feel uncomfortable. Therefore, merely increasing the frequency of communication in the workplace does not improve the 
workplace; it is the quality of communication that makes a difference. Understanding interaction processes facilitates the management and control of challenging interaction situations in the workplace. This book offers information for evaluating and improving the quality of workplace interactions.

\section{The Structure of the Book}

The book is divided into three Parts: (1) Foundations of Workplace Communication, (2) Dynamics of Workplace Communication, and (3) Developing Workplace Communication. Each Part is described in turn below.

\section{Part I Foundations of Workplace Communication}

Part I of the book establishes a framework for exploring workplace communication. Chapter 1, "Focusing on Workplace Communication", by Maarit Valo and Leena Mikkola, offers a conceptual framework for the contents of the book and presents an overview of the topics in each part.

The next two chapters discuss the basic communication structures of the workplace: Interpersonal relationships and work teams. As Leena Mikkola and Hanna Nykänen state in Chapter 2, "Workplace Relationships", interpersonal relationships form the basis for collaboration at work. The authors focus on coworker relationships, analyzing the elements of their formation, maintenance, and development. They also describe the relational processes of negotiating meanings through relational contradictions and managing identity, and of finding a balance between openness and privacy. In addition to interpersonal relationships, work teams represent another basic communication structure in the workplace. Teams and work groups are the topic of Chapter 3, "Team Communication in the Workplace", by Mitra Raappana and Tessa Horila. The authors examine important issues of teamwork, such as team building, team goals, communication tasks in teams, and team evaluation. The authors shed light on both faceto-face and technology-mediated teams.

The next two chapters take a broader perspective on the workplace. Knowledge-based work is done in both traditional face-to-face settings and digital environments. In Chapter 4, "Digital Communication Environments in the Workplace", Anu Sivunen and Kaisa Laitinen examine 
the ways in which digital environments support professional work. An appropriate digital environment facilitates workplace interaction, because it offers various platforms and provides multiple affordances to members of the workplace. The authors point out that competent digital communication requires an extensive understanding of the principles of technology use. Chapter 5, "Workplace Communication in Institutional Settings", continues with the broader perspective on workplace communication. The authors Laura Asunta and Leena Mikkola identify developments of organizational communication and their impact on professional communication. From the communication perspective, institutional organizations are of a special nature. They are influenced by societal and political discourses and thus face external challenges in their workplace communication.

\section{Part II Dynamics of Workplace Communication}

The second Part of the book presents the core dynamics of interpersonal communication and social interaction in the workplace. The aim is to illustrate the multifaceted nature of workplace communication. In Chapter 6, "Newcomers in the Workplace" by Sari Rajamäki and Leena Mikkola, particular attention is given to employees entering the workplace. Through interaction processes such as uncertainty and emotion management, role and membership negotiation, and relational and organizational identification, newcomers gradually create their sense of belonging. Chapter 7, "Meetings in the Workplace" by Tomi Laapotti and Eveliina Pennanen, discusses the role of meetings in everyday work. Meetings are commonplace, and in their repetitiveness they are ritualistic and ceremonial. Yet communication in meetings is fundamental in constructing and maintaining the workplace and making organizational processes explicit.

The dynamics of workplace communication is further untangled by Marko Siitonen and Annaleena Aira in Chapter 8, "Technology-mediated Communication in the Workplace". They state that communication technology should be approached not from the angle of technology itself but from the angle of employees' use of devices, services, and applications for communication purposes. Technology-mediated communication is a resource that enables the construction, maintenance, and development of collaborative relationships, teams, and networks. Chapter 9, Malgorzata Lahti's "Diversity and Social Interaction at Work", approaches workplace diversity from both an objective and a subjective viewpoint. The objective approach raises critical questions, but the subjective one - seeing diversity as a social 
construct - provides an informative framework for diversity at work. Different identities come into being in social interaction in the workplace.

Leader-follower relationships are examined in Leena Mikkola's Chapter 10, "Leadership in the Workplace". Although leadership may be assigned or emergent, it is always constructed reciprocally in social interaction and in interpersonal relationships. It is constituted in the mutual communication between the leader(s) and follower(s), in which meanings are managed and social influence takes place.

Negative communication phenomena in the workplace can be viewed as an integral part of communication ecosystems rather than as "the dark side of communication." Chapter 11 focuses on negative relational phenomena in workplace communication; negative relationships naturally have much in common with conflicts. In Chapter 11, "Negative Relationships in the Workplace", Sini Tuikka examines the ways in which interpersonal relationships can develop into problematic ones that include unprofessional conduct and undesirable behaviors. The most problematic involuntary relationships involve bullying, which can cause long-term emotional strain and stress, even for third parties. Successful management of negative relationships enhances a sense of control and produces well-being in the workplace.

Chapter 12, "Supportive Communication in the Workplace," by Leena Mikkola, presents the main forms and functions of social support. Supportive communication decreases emotional strain and helps employees solve a variety of work-related problems. It reinforces cooperation and the pursuit of common goals, and it has also connections to professional identity and development.

\section{Part III Developing Workplace Communication}

The third Part of this book focuses on questions of communication competence and communication development in the current and future workplace. Chapter 13 is Tessa Horila's "Communication Competence in the Workplace". Communication competence involves knowledge, skills, and attitudes that are essential in all working situations, and it can be learned and developed. Competence is often regarded as an attribute of individuals, but it can also be a shared property in a team or an organization. In Chapter 14, "Developing Workplace Communication", Leena Mikkola and Tarja Valkonen explain the process of developing 
communication in the workplace community and among its members. Developing workplace communication starts from a shared understanding of work tasks, and it continues with identifying communication practices and analyzing both work and communication processes. As the work community collaborates in pursuing common goals, communication development is needed to support the joint efforts.

In the final chapter, Chapter 15, "Future Directions in Workplace Communication", Maarit Valo and Anu Sivunen characterize the future of working life. The authors identify general indications regarding knowledge work and workplace communication in the future. It is predicted that in future work, robots will take care not only of routine tasks but significant parts of knowledge work as well. Thus, envisaging the role of human communication in future workplaces is a major challenge.

\section{References}

Alvesson, M. \& Kärreman, D. 2000. Varieties of discourse: On the study of organizations through discourse analysis. Human Relations 53(9), 1125-1149.

Bateson, G. 1972. Steps toward an ecology of mind. New York, NY: Ballantine.

Baxter, L. A. 2004. Relationships as dialogues. Personal Relationships 11(1), 1-22.

Baxter, L. A. 2011. Voicing relationships: A dialogic perspective. Los Angeles, CA: Sage.

Carvalho, T. \& Santiago, R. 2016. Professionalism and knowledge. In M. Dent, I. L.

Bourgeault, J.-L. Denis \& E. Kuhlmann (Eds) The Routledge companion to the professions and professionalism. London: Routledge, 144-157.

Clark, R. A. \& Delia, J. G. 1979. TOPOI and rhetorical competence. Quartlerly Journal of Speech 65(2), 187-206. Available at: https://doi.org/10.1080/00335637909383470.

Craig, R. T. \& Muller, H. L. (Eds) 2007. Theorizing communication: Readings across traditions. Thousand Oaks, CA: Sage.

Cushman, D. \& Whiting, G. C. 1972. An approach to communication theory: Toward consensus on rules. Journal of Communication 22(3), 217-238.

Dewulf, A., Gray, B., Putnam, L., Lewicki, R., Aarts, N., Bouwen, R. \& van Woerkum, C. 2009. Disentangling approaches to framing in conflict and negotiation research: A metaparadigmatic perspective. Human Relations 62(2), 155-193. 
Drazin, R., Glynn, M. A. \& Kazanjian, R. K. 1999. Multilevel theorizing about creativity in organizations: A sensemaking perspective. Academy of Management Review 24(2), 286307.

Fairhurst, G. T. 2011. The power of framing: Creating the language of leadership. San Francisco, CA: Jossey-Bass.

Giddens, A. 1984. The constitution of society: Outline of the theory of structuration.

Berkeley, CA: University of California Press.

Goffman, E. 1974. Frame analysis: An essay on the organization of experience. New York: Harper.

Hecht, M. L., Warren, J. R., Jung, E. \& Krieger, J. L. 2005. The communication theory of identity: Development, theoretical perspective, and future directions. In W. B. Gudykunst (Ed.) Theorizing about intercultural communication. Thousand Oaks, CA: Sage, 257-278.

Keyton, J. 2011. Communication \& organizational culture: A key to understanding work experiences. 2nd ed. Thousand Oaks, CA: Sage.

Keyton, J. 2014. Organizational culture: Creating meaning and influence. In L. L. Putnam \& D. K. Mumby (Eds) The Sage handbook of organizational communication: Advances in theory, research, and methods. Thousand Oaks, CA: Sage, 549-568.

Manning, J. 2014. A constitutive approach to interpersonal communication studies.

Communication Studies 65(4), 432-440.

Parks, M. R. 1977. Relational communication: Theory and research. Human Communication Research 3(4), 372-381.

Pearce, W. B. 2007. Making social worlds: A communication perspective. Malden, MA: Blackwell.

Pearce, W. B. \& Cronen, V. E. 1980. Communication, action, and meaning: The creation of social realities. New York, NY: Praeger.

Poole, M. S. \& McPhee, R. D. 2005. Structuration theory. In S. May \& D. K. Mumby (Eds) Engaging organizational communication theory \& research: Multiple perspectives. Thousand Oaks, CA: Sage, 171-196.

Reinhardt, W., Schmidt, B., Sloep, P. \& Drachsler, H. 2011. Knowledge worker roles and actions: Results of two empirical studies. Knowledge and Process Management 18(3), 150 174.

Sias, P. M. 2009. Organizing relationships: Traditional and emerging perspectives on workplace relationships. Los Angeles, CA: Sage. 